\title{
The Impact of Leadership on the Motivation of Hotel Employee During the Pandemic Era: Evidence from Greece
}

http://doi.org/10.21272/bel.5(3).22-41.2021

Aivalioti Ypapanti, ORCID: https://orcid.org/0000-0002-3087-1291

MSc, Tourism businesses administration, Hellenic Open University, Patra, Greece

Mary Constantoglou, ORCID: https://orcid.org/0000-0002-4365-3349

$\mathrm{PhD}$, Adjunct Lecturer, Department of Economics and Tourism Management, University of Aegean, Chios, Greece

\begin{abstract}
Human Resources Management (HRM) plays a catalytic role in the positive performance of a hotel. The Covid-19 pandemic struck the tourism sector to an unprecedented degree at a time when the industry was unprepared for such a severe health crisis. Maintaining the smooth operation of hotels during the crisis presupposes new financial planning, new services according to the health protocols, or modification of those already provided. Under this situation, staff training is necessary. The purpose of the present paper is to examine the impact of leadership on the motivation of hotel employees during the COVID19 pandemic. The value of leadership in the formulation and acceptance of a common vision is also explored. Furthermore, the paper examines how the leader directly or indirectly guides employees towards serving the vision while pointing out those human characteristics that are valuable for such a process. At a second level, the research aims to highlight the leader's individual practices to motivate employees to increase productivity and, therefore, to improve the services provided. The research took place in the Greek islands of Rhodes and Kos during February and March 2021. Primary data were collected using a questionnaire sent to the leaders of all four- and five-star hotels of those two islands. A total of 150 usable questionnaires were gathered and analyzed. The results showed the new conditions faced by leaders and managers are related to the individual fears of employees and the barriers they are facing in their personal lives according to their safety. These factors cause reluctance or work stress to hotel employees, whether they are purely work-related or derived from family or other backgrounds, affecting their efficiency. Therefore, increased empathy is required for leaders to see the insecurities and needs of employees. Conversely, managers should activate employee empathy to understand the needs of their colleagues and customers and serve the common vision of the hotels. At this point, leaders must stand as guarantors of security and be a source of inspiration.
\end{abstract}

Keywords: Leadership, Motivation, Decision Making, Quality Management, Hotels, Post-COVID19 Era.

JEL Classification: L83, Z31, Z30, Z32, Z33, Z38.

Cite as: Ypapanti, A., Constantoglou, M. (2021). The Impact of Leadership on the Motivation of Hotel Employee During the Pandemic Era: Evidence from Greece. Business Ethics and Leadership, 5(3), 22-41. http://doi.org/10.21272/bel.5(3).22-41.2021.

\section{Received: 17 July $2021 \quad$ Accepted: 25 August $2021 \quad$ Published: 13 September 2021}

Copyright: (C) 2021 by the author. Licensee Sumy State University, Ukraine. This article is an open access article distributed under the terms and conditions of the Creative Commons Attribution (CC BY) license (https://creativecommons.org/licenses/by/4.0/).

\section{Introduction}

The hospitality industry is highly dependent on cross-border travel and transportation. Due to the Covid-19 pandemic, the cessation of these processes has plunged the tourism sector and hotels, regardless of size, into recession. In the upcoming season, it is considered necessary for hotel operators to use all the knowledge and skills related to crisis management and to activate all productive resources for companies to get out of the current impasse (Yacoub, ElHajjar, 2021). The need for immediate and rapid recovery of hotels after a long suspension period is a bet for hotel managers. Ensuring sustainability in an intense and diversified field of competition is left to unprecedented processes and increased demands related to the conditions created by the pandemic each time. Attracting customers and keeping up to their expectations with the services provided presupposes the hotel's personnel to be adequately trained according to health protocols. To make this possible, hotel managers and, more precisely HR Managers, need to understand the specific needs of employees at this 
time of crisis and devise strategies, possibly personalized, to mobilize employees and achieve their best possible performance.

The purpose of the present paper is to determine the role of the HR Manager in the efficient operation of a hotel during the COVID-19 pandemic. The value of leadership in forming a common vision, for which all the staff of the unit should work, is especially explored. The paper examines how the leader directly or indirectly guides employees towards serving the vision, while pointing out those human characteristics that are considered valuable for such a process. At a second level, the research aims to highlight the individual practices, which, as part of methodical planning, motivate employees to increase their productivity and, therefore, to improve the services provided. The basic questions that this paper is trying to answer are first, to what extent do the managers' strategies contribute to the achievement of the goals of the hotel business? Is it legitimate for managers to penetrate the unit strategy and influence the direction of their decisions and practical applications? Secondly, what are the new needs that arise for the hospitality sector employees in the current conditions of the health crisis? Changing priorities based on employees' personal needs can affect their performance and productivity? What are the points on which the manager focuses when motivating employees to meet these needs? And finally, what is the change in the concept and role of the leader during the pandemic? How do the safety and health components affect the leader's vision and goals and how the unit's rhetorical and communication policy is shaped towards employees?

\section{Literature Review}

Research has shown the catalytic importance of HRM practices and employee motivation methods for hotels' efficient organization and operation (Kehoe \& Wright, 2013). Theoretical and practical models have been developed to demonstrate the relationship between HRM practices and their positive and negative effects on employees and customers. Employee satisfaction is considered essential for acquiring customers and maintaining a market share (Hashim et al., 2016). Research shows that the cost of attracting a new customer is five times higher than retaining an existing one, given the development or marketing strategy required to acquire a new customer base (Hashim et al., 2016). At the same time, customer satisfaction has been recognized as a significant predictor of a hotel's financial performance and a reliable source for word-of-mouth marketing. Therefore, for hotels to gain a competitive advantage and increase their market share, they must focus on customer satisfaction. Customer satisfaction, however, depends mainly on the service of the first line of employees. Therefore, employee satisfaction is considered just as important. Job satisfaction works as a mediator for customer satisfaction because satisfied employees work and give their best possible performance. Customer satisfaction is affected by the value of the services provided, which the satisfied and therefore productive employees create.

In this light, the organization and management of human resources is the right way to serve guests and the main way a hotel organization can develop long-term relationships with customers (Najam et al., 2020). However, motivating employees is not an easy task, as what ultimately works is employees' perception about the practices of HR. More precisely, regardless of the goals that managers set in the process of mobilizing employees, more important is the sense of justice that employees really have as a result of these practices. Especially in critical times, the feeling of fair treatment is heightened in the employees, who, given the circumstances, demand to a greater extent the satisfaction of their needs. Thus, the sense of justice plays a central role in the connection between managers' practices and work outcomes because it enhances the employee's commitment to the organization and its goals (Najam et al., 2020).

In this case, what is required is the development of overall positive behavior of employees to achieve correspondingly positive behavior from the visitors. The main way to achieve this positive behavior is hidden in the employee's relationship with their colleagues and visitors of the hotel and, more precisely, in their relationship with the hotel's management. Therefore, these three aspects must be covered by the HR practices when designing and implementing employee management and motivation programs (Laskarin, 2017). The survival of hotels after the pandemic and its consequences in the tourism industry is the focus of discussions between the hotel owners, department managers, and the state. This fermentation is useful in the short term because it allows focusing on the immediate issues and dangerous conditions that have resulted from the reduced operation or inactivity of hotels. However, at the business level, the constant vigilance, and the anxious development of reflexes to deal with immediate problems can, in the long run, undermine the broader perspective and perception an organization must have to survive in a fast-changing market (Nichols et al., 2020). Procedures that involve more profound control of the business operations or considerations for the development of the wider hotel sector are also helpful for the hotel's recovery after a generalized crisis. 
For this reason, a broader view of the company's situation, but also of the financial sector in which it is part, is a process that must continue and not be suspended for the sake of immediate reactions to this treaty (Nichols et al., 2020). Accordingly, in the current crisis in the hospitality industry caused by the COVID-19 pandemic, the managers of all the hotel departments should realize that the response to this crisis is only the first stage in a multi-level reorganization plan. The persistent pursuit of spending cuts and budget reduction may partly solve the problem of lack of revenue. Still, it cannot lead to innovative practices that meet the visitors' and employees' new hygiene conditions (Nichols et al., 2020). The current crisis shows that these changes are necessary. Therefore, a wider view of the current economic, political, and psychosocial environment is also considered necessary (Agarwal, 2020).

The Concept of Competent Leadership. Recent research on business management converges that one of the key factors for the survival of companies in times of crisis is the protection and proper functioning of working groups. HRM strongly depends on the leadership style that the manager applies, and the range of his/her skills determines the effectiveness of the organization's employees (Kara et al., 2013). Thus, in the post-pandemic era, competent and effective leaders must be aware of the new conditions under which employees are called upon to perform their duties. They will also need to understand the distractions that employees face to discover the most appropriate ways to mobilize them and communicate the new collective goals. The information about the latest developments and the reactions of the hotel to the health crisis should be disseminated equally and clearly to all members to ensure that the entire workforce understands the current circumstances and the respective directions of the company. The capable leader should therefore find or open channels of communication with the employees and ensure that the new goals will be understood and followed by all (Susser and Tyson, 2020).

Transformational Leadership. Although a health crisis is being considered in the present case, the financial implications are immediate and far-reaching. Therefore, hotel managers should be able to constantly redefine priorities to ensure that, despite the stressful environment, there is a consistent alignment of the employees with the business objectives. Regardless of the size of the hotel, hotel executives should be able to lead employees beyond their fears or personal interests, changing their ethics and values tow ards a common vision (transformational leadership) (Gui et al., 2020). Daily they should seek personal contact with employees, with whom they should first form personal ties and then focus on work issues. It has been observed that during crises, employees turn to managers more often to receive guidance on how to respond more effectively to their tasks and, therefore, the existence of a relationship of trust is considered helpful and necessary (Susser and Tyson, 2020). Especially with the prevalence of remote work, which, in the case of hotels, can be applied only in certain departments and at middle management levels, the risk of confusion and disengagement from the common goal is greater. A deeper connection between partners is required to avoid the communication stalemate (Susser and Tyson, 2020).

Allocation of Responsibilities. Although it is the responsibility of the leaders to guide the teams according to an action plan, the implementation of this plan is not necessary or cannot be an individual matter. Therefore, a capable leader, especially during a pandemic crisis where stress is a constant quality factor, should seek the help of their colleagues to implement their plan. By recognizing the structure, hierarchy, and capabilities of each department, the general manager, the human resources manager, and the hotel departments' managers can and should assign the work to individuals. Centralization in the execution of activities can also cost the manager the time and clarity required to control the processes and results or to explore the bigger picture. At the same time, a crisis like the pandemic is the ideal condition for managers to assess the abilities of the people they manage. They can identify which employees responded satisfactorily to immediate reflex needs, which had difficulty or disorientation, and why. The results of this feedback will indicate which employees are appropriate to meet the interests of the hotel also during the post-pandemic period (Susser and Tyson, 2020).

The Leader as the Guarantor of Security. For the orthodox operation of the hotel during the pandemic and after the lifting of the strict restrictions, it is necessary to develop a sense of security and the provision of health care. The more protected and informed the employees feel, the better they will be able to convey the feeling of security and control to the customers, contributing to the increased quality of the provided services. The inculcation of trust in the workforce is achieved mainly by the leaders' formality and relative care and is a difficult process. Training of employees on how to prevent the spread of the virus, how to deal with possible infection of a person in the work environment, and, how to recognize the symptoms is essential. It is also crucial both for the practical issue of protecting employees' health and controlling the spread of the virus and for cultivating a "corporate ethic" that prioritizes health. This ethic can very well work to motivate employees, who feel exposed to health risks, due to daily personal contact with other staff members and customers (Zhang 
et al., 2020). Managers should communicate to employees the specific state public health guidelines with which the hotel is aligned for staff to feel safe. In terms of the strategy to be followed in dealing with cases in the work environment, it is important not to discriminate or target people who are ill or have symptoms on the one hand, so as not to hide incidents and, on the other hand, not to create dissatisfaction, which will ultimately jeopardize the quality of services (Susser and Tyson, 2020).

Leadership and Empathy. Even if we assume that the hospitality industry will return to full operation next season, the forecasts for the tourist traffic show that hotels will accommodate a much-reduced percentage of visitors at least with one exception in the third quarter of 2021, when a relative increase of arrivals is expected (UNWTO, 2020). The staffing of the hotels will be reasonably limited to the minimum necessary staff, while, given the seasonality, it will not be possible to ensure the duration of employment of these employees from the beginning. Job insecurity will be a pathogen present for a long time in hotel organizations and this means that human resources managers will have to reorganize and provide up-to-date incentive plans for their employees (Carnevale, Hatak, 2020). In this context, leaders need to identify threats posed by their subordinates and take steps to address these issues. Establishing close relationships with team members they lead eliminates the belief that managers themselves avoid issues that are considered important by employees. It has been observed that employees are more sensitive to issues directly related to their daily work life, such as conversations and behaviors (Yang and Lau, 2019). The manager's ability to forge closer ties with their subordinates can, thus, help alleviate concerns and prevent employees from resigning. This process requires a developed empathy. The manager can perceive emotions and identify the corresponding needs of employees to a point where it can be identified with their psychological state. This identification allows them to perceive situations that can motivate employees and shape them (Bradberry \& Greaves, 2006). Especially in times of generalized crisis, the development of empathy and social intelligence is a necessary skill for hotel managers because they are called to respond to unfamiliar emotions and even in an industry where physical and interpersonal contacts are inevitable.

The Variables of Willingness and Ability. In times of crisis, employees can be absent from their job duties. The percentage of absence is affected by two important variables, the degree of willingness of the employee to work and their ability to fulfill their responsibilities. In this context, the concept of ability is related to the ability of the individual to cope with their tasks, while the concept of willingness is related to the determination of the individual to cope with their tasks (Qureshi et al., 2005). In a health crisis, the variables of willingness and ability are most affected by the exposure fear to the virus. Especially in the field of hospitality, where personal contact with colleagues and clients is extensive (Verikios et al., 2016), employees feel exposed to health risks at the same time as they bear the burden of implementing pandemic measures (Hu et al., 2020). It is necessary to understand it in the first stage to reduce the phenomenon (Karatepe et al., 2020). The manager should identify the factors that may act as a deterrent to employees, jeopardize the adequacy of the hotel in staff and, therefore, threaten the provision of quality services (Stergiou, Farmaki, 2020).

The variables of ability and willingness depend on the barriers that appear in the work and social environment and on the percentage that those are considered negotiable or not. The more difficult it is for the employee to decide on their presence at work, the more likely it is that deterrents will be considered real obstacles. Of course, in this discussion, there is a high percentage of relativity. If, for example, the decision-making process depends on the money factor, it is understood that the employee with higher earnings will decide more easily. In comparison, the lower earnings will find it difficult and consider the issue an obstacle. In practice, the task of managers is to act so that the factors that affect the willingness and ability of employees in the pandemic era are not considered obstacles. (Stergiou, Farmaki, 2020).

New Factors Causing Work Stress. Past research has shown that stress negatively affects employees in terms of job satisfaction, commitment towards it, and performance (Yang and Lau, 2019; Kim et al., 2015). In the present condition, hotel employees experience intense stress as a psychological reaction to an unfamiliar and abnormal condition, which affects all areas of their lives. In many cases, stress leads to reduced job satisfaction and resignation in the worst case. Hotel policies such as unpaid leave, reduced working hours, cuts in salaries, or non-payment of overtime and compensation are of concern to employees, as their confidence in management is shaken. Employees feel vulnerable at work, precarious, and consumable. This concern shakes the satisfaction of the employees from their work and loosens the commitment they feel towards the goals of the hotel.

The research of Wong et al. (2020) on the factors that cause work stress in hotel employees before and after the pandemic outbreak proves a severe change in the quality parameters of these factors. Before the pandemic, traditional factors of work stress were workload, long working hours, limited privacy due to increased demands, standardization of work, and lack of cooperation with other staff. Factors related to unethical work 
practices on behalf of the management or unstable policies were found to be much lower in the statistical results. On the contrary, after the pandemic outbreak, the hotel staff's attitudes and behaviors seem to be different, as evidenced by differentiation in the factors that explain work stress (Wong et al., 2020). Employees' job satisfaction, commitment to the business, efficiency, individual well-being, and social behavior seem to be declining due to the failure of their work environment to eliminate the stress of new pandemic data. It turns out that hotel employees are willing to ignore traditional stressors in a global financial crisis because they still retain the ability to work and earn in a time of cuts, layoffs, and unemployment (Wong et al., 2020). Even further, salary cuts during the pandemic are likely to be perceived by employees as an attempt by the hotel management to help its employees overcome current difficulties rather than making redundancies. This somehow employer support eventually increased job satisfaction and business commitment (Wong et al., 2020).

The Theory of Resource Conservation. Following the pandemic experience, restoring employees 'faith and confidence in hotels' efforts to maintain a safe and stable working environment is a critical psychological process that determines individuals' broader behavior and performance (Liu-Lastres et al., 2019). The method of restoring employees' trust in the organization in times of crisis is the work of a management practice called "safety leadership". The safety leadership strategy works by creating inherent motivation in employees. By guiding and caring for employees' safety measures, the organization seeks to inculcate in them the value of collective care and vision for common issues, automatically resulting in motivating employees. The latter feel that they are working for a higher common goal related to security in a time of crisis. This tactic is based on the theory of resource conservation, which suggests that individuals try to save resources that they value in the face of real or potential threats in times of stress. Crises, such as the pandemic, can destroy valuable employees' resources. By acting as an inherent psychological resource, restoring employees' beliefs about the organization can prevent them from losing motivation and help them cope with stress. Therefore, the restoration of beliefs is a prominent and motivating psychological variable, which supports the impact of the overall strategy for employee safety followed by the organization. In the present case, of course, the perceived risk and its extent reduce the correlation between "safety leadership" and the variable of the restoration of beliefs concerning a potential risk. Nevertheless, "safety leadership" is still effective in motivating employees at a time when their values have been completely redefined (Zhang et al., 2020).

Recent research (Zhang et al., 2020) on the security strategy in the hospitality industry during the pandemic has shown that its impact on employee security-related behavior has been positive. Employees have achieved positive results in terms of compliance with the rules, adaptation to new working conditions and participation in training programs and even consistently (Xue et al., 2020). The safety strategy followed had the most significant impact on employees compared to other traditional stimulus tactics. It demonstrates that the safety strategy encourages employees to comply with the instructions, maintain safety, and acquire new relevant skills, contributing greatly to improving the overall image and performance of the hotels they work for. On the issue of restoring hotel employees' beliefs, it has been observed that the perceived risk of a pandemic, the severity and the sensitivity required by the present conditions have mitigated the impact of the safety strategy and hampered the process of suggestions from organizations. Thus, it turns out that the more perceived the risk, and, therefore, the lower the rate of recovery of employees' beliefs, the weaker the impact of safety leadership on hotel employees. In the aftermath of the pandemic, however, when the danger is perceived, but to a lesser degree, security leadership can be more effective.

Providing Psychosocial Motivation. During the pandemic, the hotel human resources department practices, which seem to have benefited both the hotels in terms of performance and the staff, have exceeded conventional limits in meeting the needs. In other words, these practices were not limited to purely labor issues. Still, they were extended to employees' personal lives to respond to concerns, limiting their productivity. According to the results of a recent study on the prosperity rates of hotel staff in India in 2020 (Agarwal, 2021), the most effective practices of motivating employees were those that considered their personal lives, since the limits of personal and professional life were, in the present critical phase, blurred. Thus, the human resources strategy dictates that incitement must be applied within the organization's boundaries and its core activities. Even in line with the employer's interest, it seems to be effective in a critical period such as the pandemic. In addition to the need to extend incentives to issues related to employees' personal lives, such as the need for safety and family protection, modern research shows that incentive strategies should aim at employee well-being so that they positively impact performance and the overall performance of the organization. It is how mutual profit is produced. The same research emphasizes that job insecurity and stress can, of course, affect the well-being of employees, but they do not necessarily reduce their performance. If, in times of uncertainty, marketing strategies provide clear information and employees feel confident about the availability of future resources, they perceive the requirements as challenges that need to be overcome. Employees, therefore, consider that their work is worth the investment of their personal resources (Agarwal, 2020). 
In this context, research on hotel staff in India has shown that the resources that mobilize staff are divided into two levels, the internal-organizational and the family. At the organizational level, i.e., within the company's boundaries, the resources that enhanced employee well-being are related to consistency in communication and information flow, the creation of positive relationships between employees, authentic leadership guidance, and support on the personal problems of each employee. Thus, employees with a history of good relationship with their manager had moderate demands for their work, even though they were aware of the total injustice and breach of trust shown by the organization. It is due to the resource pool of these employees, which allows them to continue investing even in times of crisis, because they expect future profits. These strategies increase both the well-being of employees and their resilience to meet the challenges. The performance of employees also increases in a chain; therefore, the quality of the provided services is also upgraded (Salas-Vallina et al., 2020). At the family level, employees with healthy family relationships, who received relative support from family members, recorded lower isolation levels. This fact confirms the importance of building stable interpersonal relationships to overcome any crisis. On the contrary, the maintenance burdens of a household, loneliness, troubled relationships with family members, and poor housing conditions led to an increase in employees' stress in pandemic conditions and limited the resources they could devote to their work. Inductively, trying to meet certain needs related to family life can enhance individuals' resources that are used to deal with a crisis. Managers should, therefore, consider ways soon that can help employees manage their personal issues to increase their well-being and overall performance in their work (Agarwal, 2020).

\section{Case Study Area: The Islands of Rhodes and Kos, Greece}

The Dodecanese Islands (Map 1) is a popular tourist destination for both foreign and domestic visitors. Prolonged periods of clear weather combined with the geophysical wealth of the islands make the Dodecanese an ideal destination for most of the time and different individual travel purposes. The various cultural treasures of the islands and the rich folk tradition, which is formed by an alloy of cultural influences on the indigenous island population, serve in the same direction.

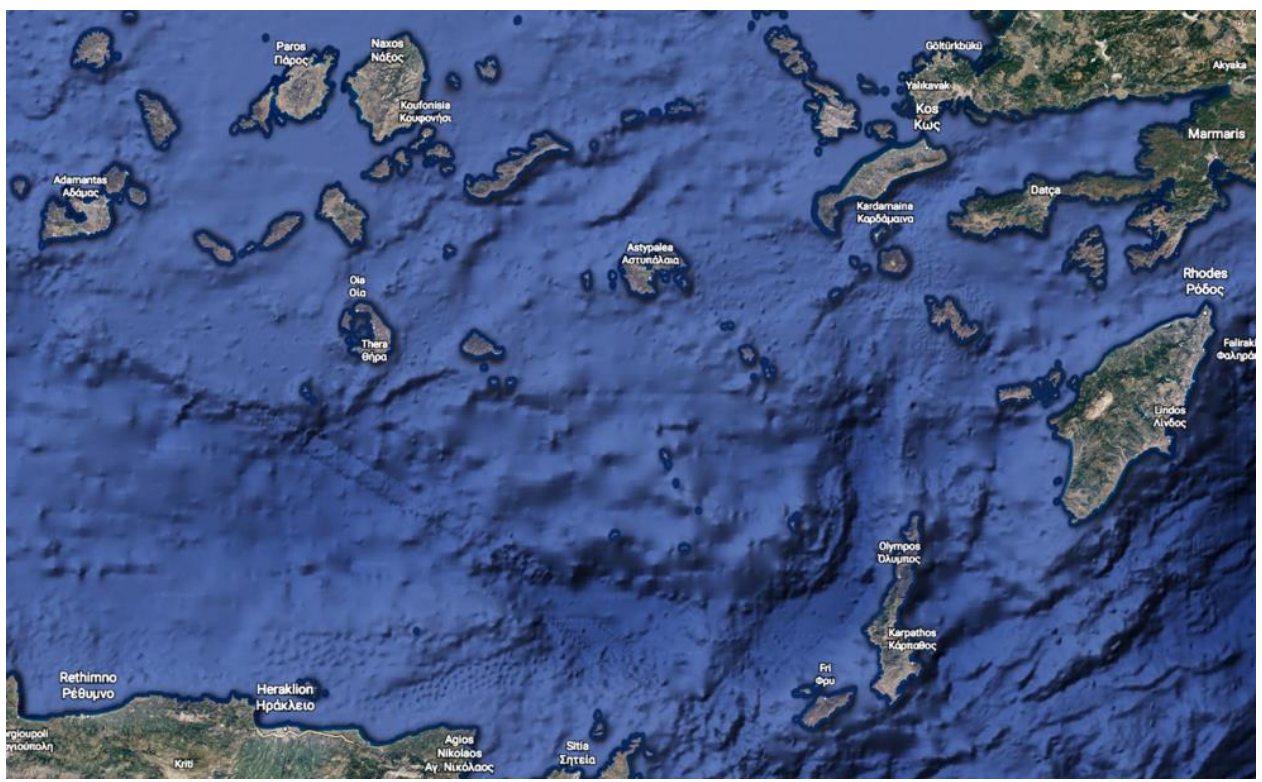

Figure 1. Dodecanese Islands

Source: Google Earth 2021

Rhodes is one of the most popular tourist destinations in Greece and the most visited island of the Dodecanese due to its natural beauty and cultural interest (Institute of the Association of Greek Tourist Enterprises, 2020). Regarding the hotel infrastructure of the island, Rhodes has units of all categories, from hostels to five-star hotels, serving the needs of a diverse audience (Table 1). In its territory, $60 \%$ of the rooms of the Dodecanese is located with a total of 537 units and 100,212 beds. Respectively in Rhodes, 55\% of the rented rooms of the Dodecanese is concentrated, with a total of 14,454 beds; however, there are no organized camping structures (Institute of the Association of Greek Tourist Enterprises, 2020). Kos is another island in the Dodecanese, which annually welcomes many tourists from Greece and abroad due to the alternative experiences it offers. It has all categories of accommodation, covering the needs of different types of guests. 
Table 1. Bed Capacity of Rhodes and Kos

\begin{tabular}{|l|c|c|}
\hline & Hotel Beds (2019) & Rent Rooms (2019) \\
\hline Rhodes & 100,212 & 14,454 \\
\hline Kos & 55,598 & 5,855 \\
\hline
\end{tabular}

Source: INSETE, 2020

According to the annual report of the Institute of the Association of Greek Tourist Enterprises for 2020, Kos gathers $33 \%$ of the total hotels of the Dodecanese, i.e., it has 282 units with a total of 55,598 beds, with $34 \%$ of them being in 5-star hotels. Respectively, the island gathers $23 \%$ of the rented rooms of the Dodecanese, while it has one organized camping unit (Institute of the Association of Greek Tourist Enterprises, 2020). The growing tourism trend in Rhodes and Kos until 2019 was unexpectedly stopped by the Covid-19 pandemic (Table 2), which reasonably paralyzed the tourism industry worldwide. Given the tourist season of 2021, it is a bet whether the tourist destinations will be able to recover and overcome the problems caused by the suspension of the operation of the tourist structures. At the same time, the formation of competition is interesting, as in addition to the traditional factors that shape supply and demand, in this condition there are factors related to the health policy followed in the destinations, the resilience of the tourist infrastructure, and the reflexes of the actors involved in developments.

Table 2. International Arrivals in the Airports of Rhodes and Kos

\begin{tabular}{|l|c|c|c|}
\hline & $\begin{array}{c}\text { International Tourist } \\
\text { arrivals (2019) }\end{array}$ & $\begin{array}{c}\text { International Tourist } \\
\text { arrivals (2020) }\end{array}$ & Change \% \\
\hline Rhodes & $2,365,520$ & 599,606 & $-74,7 \%$ \\
\hline Kos & $1,196,217$ & 333,387 & $-72,1 \%$ \\
\hline
\end{tabular}

Source: Fraport Greece (https://www.fraport-greece.com/ell/), 2020

The survey questions of the present study attempt to investigate the degree of readiness of the hotels of the two islands regarding the human resources management in the time of the health crisis, to provide quality services to customers.

\section{Methodology}

The Survey Method. The quantitative approach was chosen for this survey. This type of survey is based on collecting information resulting from data measurements, which can be either quantitative or qualitative. Data analysis is undertaken with the use of specific statistical techniques. The main survey instrument in a quantitative survey is the structured questionnaire (Creswell, 2011), used in this survey and presented in detail below. The quantitative approach was considered appropriate since its purposes include the investigation and description of the views and beliefs of hotel executives. Finally, the quantitative survey is used primarily to confirm existing theories (Creswell, 2011; Cohen, Manion \& Morrison, 2008; Cohen, Manion \& Morrison, 2018).

The Survey Instruments. A semi-structured questionnaire was used to conduct the quantitative survey, which was based on survey questionnaires with the same or similar subject, to increase the validity and reliability of the answers. The use of the questionnaire provides extensive information from a large sample in a short period. Also, this method of collecting primary data can ensure the anonymity of the participants, which contributes to the greater reliability of the answers and is relevant to GDBR. The first part of the questionnaire included demographic questions, such as gender, age, position, and professional experience. The second part had questions about the management of hotel staff during the pandemic.

Most of the questions in this section were closed-ended, especially belonging to a five-point Likert scale, with answers ranging from "Not at all" to "Very much". The reasons that led to the choice of this type of questions were the possibility they provide to the researcher for easy comparison of the answers and their ease of coding. The fact that they do not give the freedom of answers to the user is mentioned as an important disadvantage of this type of questions (Creswell, 2011), and, for this reason, the questionnaire also included three open-ended questions. Finally, the standardization of the classification of Likert-type questions allows the analytical and statistical processing of the collected data, the formation of corresponding groups, and the quantitative estimation of the size of each group. In addition, the focus was on the clear content of the questions, being worded, small, simple, and understandable. At the same time, an effort was made to arouse the participants' interest and encourage them to answer honestly. Before drafting the final questionnaire, a pilot questionnaire was distributed to 5 hotel executives who did not participate in the last survey, to identify possible ambiguities and duplications in the questions. Finally, the statistical analysis of the data was implemented with the statistical program SPSS v22., using appropriate Descriptive Statistics instruments. 
The Survey Samples. No specific sampling method was used for this survey, i.e., it is a convenience sample (Creswell, 2011). It is worth noting that even a convenience sample can provide important information about the population of a survey. More specifically, the participants in the survey, i.e., hotel executives, completed the questionnaire electronically from February 25 to March 5, 2021. The questionnaire was created on Google forms and distributed to all participants electronically through the Rhodes \& Kos Hotel Managers Association. The researcher contacted the association based on the logical thinking that the association has the managers' contact details of the 4- and 5-star hotels on the islands of Rhodes and Kos, which, after all, constitute the survey population. Regarding the $5^{*} \& 4^{*}$ hotels in Rhodes and Kos, according to the Hellenic Chamber of Hotels, there are 269 hotels (in Rhodes there are $635^{*}$ hotels and $1234^{*}$ hotels, while in Kos $395^{*}$ hotels and 44 4* hotels.

The hotel managers' associations in Rhodes and Kos sent the questionnaire to 456 members (general managers, deputy managers, human resources managers, food department managers and rooms division managers). 150 useful questionnaires were sent back and were used for statistical analysis. The questionnaire was accompanied by a letter, which stated the purpose of the survey, and encouraged participants to respond to it both to ensure their anonymity and for the short time required. The sample is not considered representative of the population, which is the total management of hotels, and this is a significant limitation of the survey (Creswell, 2011).

\section{Results and Discussion}

Regarding the gender of the participants in the survey, most of them were men (Figure 1). More specifically, $58.67 \%$ ( 85 people) were men and $42.33 \%$ (65 people) were women.

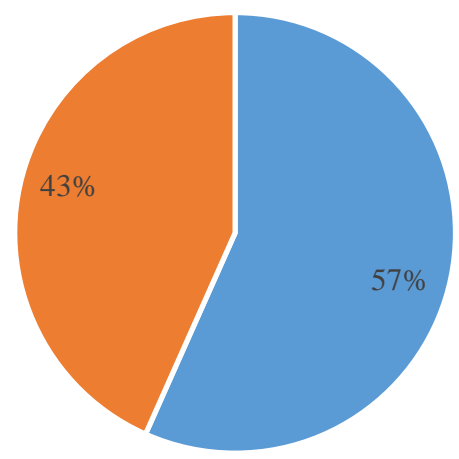

Figure 1. Sample Gender Demographics

Source: Survey Data

Regarding their age (Figure 2), most of them belonged to the age group from 41 to 50 years. More specifically, $34.67 \%$ ( 52 people) belonged to the age group from 41 to 50 years, $31.32 \%$ (47 people) belonged to the age group from 31 to 40 years, $20 \%$ (30 people) belonged to in the age group from 51 to 60 years, $8 \%$ (12 people) belonged to the age group up to 30 years, and finally, $6 \%$ (9 people) stated that they were over 60 years old.

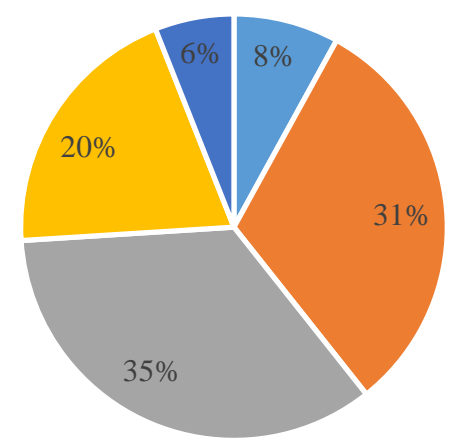


According to Figure 3, 46.67\% of the respondents (70 people) held the position of General Manager, while $22.67 \%$ (34 people) held the position of Manager of the Rooms Division Department. Finally, $18 \%$ (27 people) held the position of Manager of Food Services and 12.67\% (19 people) held the position of Head of Human Resources.

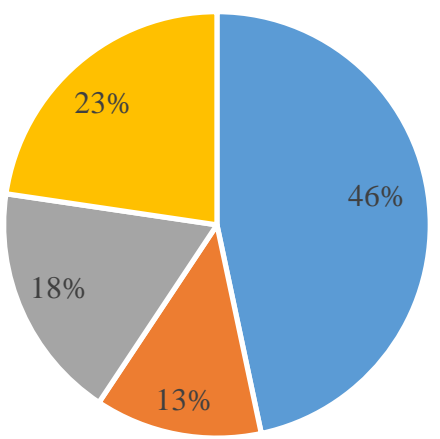

Source: Survey Data

Figure 3. Job Position

Regarding their years of experience (Figure 4), most participants stated that they have more than 20 years of professional experience. More specifically, 37.33\% (56 people) answered that they have professional experience over 20 years, $18.67 \%$ ( 28 people) from 11 to 15 years, 16.67\% ( 25 people) from 6 to 10 years, $14 \%$ (22 people) up to 5 years and finally $13.33 \%$ ( 20 people) answered that they have professional experience from 16 to 20 years.

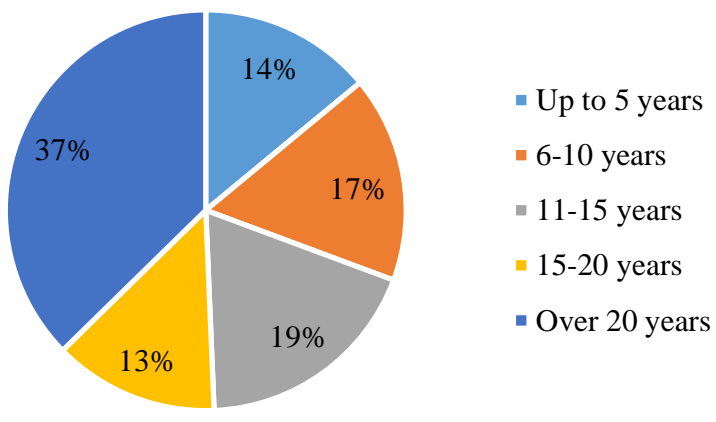

Source: Survey Data

Figure 4. Years of Experience

Leadership and Motivation of Workforce. In the first question of the section, the survey participants were asked to state to what extent they consider the following to serve as work incentives in the hotel during the pandemic. Their answers are presented in table (3) below:

Table 3. Work Incentives

\begin{tabular}{|l|c|c|c|c|c|}
\hline & Not at all & Little & To some extent & Rather much & Very much \\
\hline Earnings & $2.7 \%$ & $8 \%$ & $12.7 \%$ & $44 \%$ & $32.7 \%$ \\
\hline Flexible schedule & $4.7 \%$ & $12 \%$ & $30.7 \%$ & $37.3 \%$ & $15.3 \%$ \\
\hline Personal time & $3.3 \%$ & $9.3 \%$ & $38 \%$ & $32.7 \%$ & $16.7 \%$ \\
\hline Taking responsibility & $3.3 \%$ & $4 \%$ & $34 \%$ & $37.3 \%$ & $21.3 \%$ \\
\hline Sense of cohesion & $3.3 \%$ & $8 \%$ & $23.3 \%$ & $38 \%$ & $27.3 \%$ \\
\hline Feeling of security & $4 \%$ & $2 \%$ & $14.7 \%$ & $25.3 \%$ & $54 \%$ \\
\hline Autonomy & $3.3 \%$ & $10.7 \%$ & $30.7 \%$ & $39.3 \%$ & $16 \%$ \\
\hline
\end{tabular}

Source: Survey Data

From the above table, it seems that security is considered the most important motivation (79.3\% Rather Much or Very Much). It is followed by earnings (76.7\% Rather Much or Very Much), the sense of cohesion (65.3\% Rather Much or Very Much), taking responsibility (58.6\% Rather Much or Very Much), autonomy (55.3\% 
Rather Much or Very Much), flexible schedule (52.6\% Rather Much or Very Much), while personal time ranks as the lowest of all (49.4\% Rather Much or Very Much). Participants were then, asked to answer the extent to which they considered it helpful under the current conditions of the pandemic to deepen the personal relationships between the employees and the human resources manager (Figure 5). From the chart below, it seems that most of them agree since $89.34 \%$ (134 people) answered that they agree Rather Much or Very Much. Also, $7.33 \%$ (11 people) answered that they agree to some extent, while finally, $3.33 \%$ (5 people) answered that they agree Little or not at all.

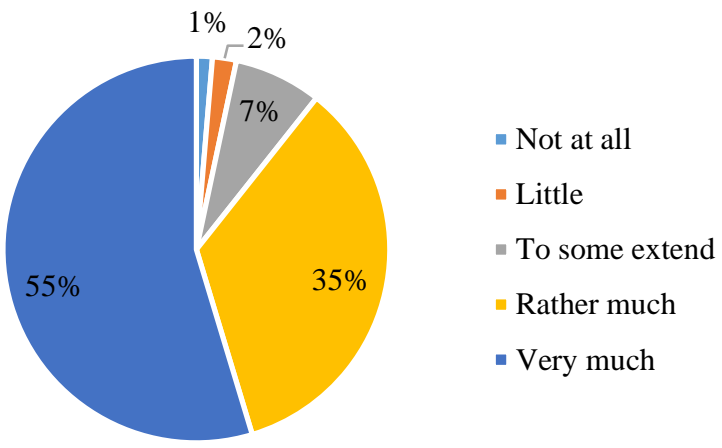

Figure 5. Deepening Personal Employee Relations with HRM during the COVID 19 Pandemic

Source: Survey Data

In the next question they were asked to what extent they believe the Human Resources Department (HRD) can help foster an atmosphere of safety in the workplace (Figure 6). From the chart below it seems that most of them agree, since $92.67 \%$ (139 people) answered that they agree Rather Much or Very Much. Furthermore, $6 \%$ (9 people) answered that they agree to some extent, while finally $1.33 \%$ ( 2 people) answered that they agree Little.

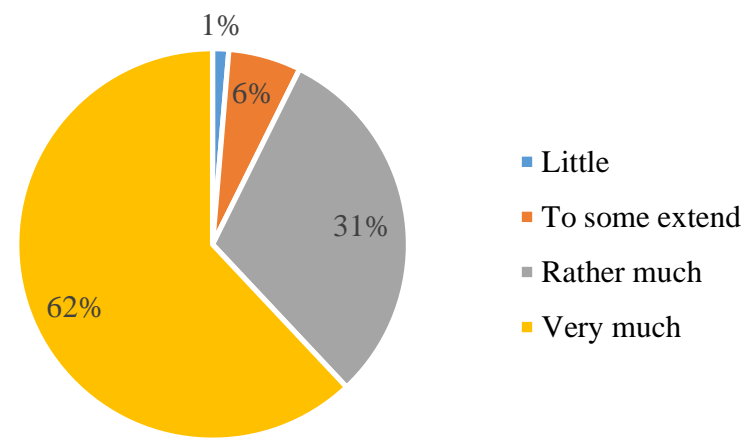

Figure 6. HR Department and Its Ability to Create a Climate of Safety at Workplace

Source: Survey Data

In the question to what extent, they believe that the involvement of working groups in the decision-making process on labor issues is helpful (Figure 7) most of them agree, since $85.34 \%$ (128 people) answered that they agree Rather Much or Very Much. Also, 10.67\% (16 people) answered that they agree to some extent, while finally $4 \%$ (5 people) answered that they agree little. 


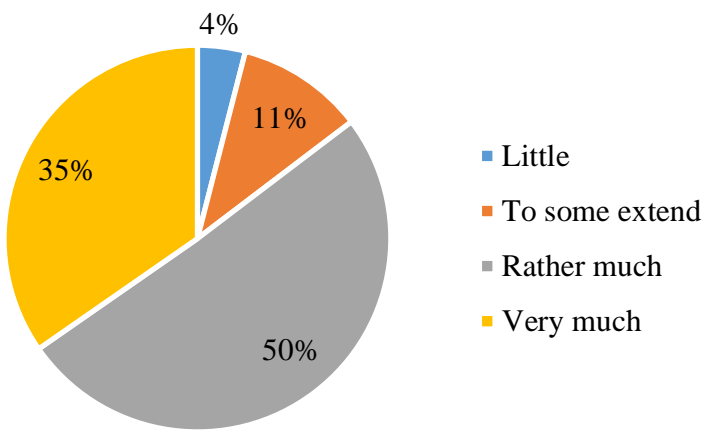

Figure 7. Importance of Working Groups in Decision Making Process

Source: Survey Data

When asked to what extent they believe HRD can guide staff behavior in matters of prevention and safety (Figure 8) most of them agree, since $88.66 \%$ (128 people) answered that they agree Rather Much or Very Much. Furthermore, $10 \%$ (15 people) answered that they agree to some extent, while $1.34 \%$ ( 2 people) answered that they agree Little or not at all.

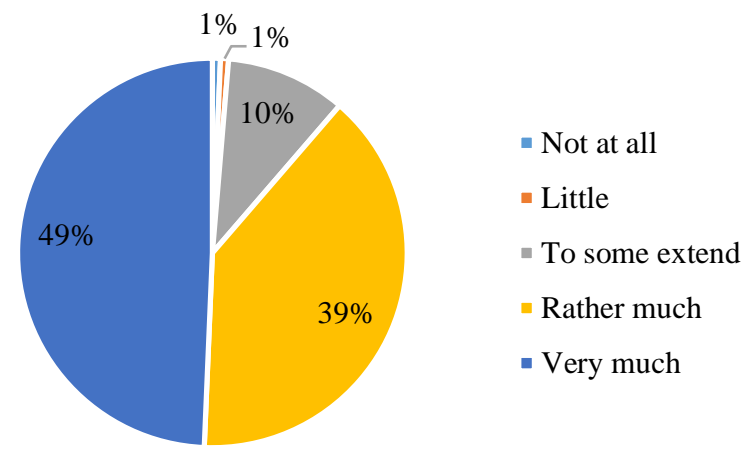

Figure 8. HRM and Behavior Guidance to Preserve Safety

Source: Survey Data

Further, when asked to what extent they believe that the ability of staff to cope with the disorienting factors of the pandemic should be measured to their overall evaluation (Figure 9) it seems that most of them agree, since 73.33\% (110 people) answered that they agree Rather Much or Very Much. Furthermore, 24\% (36 people) answered that they agree to some extent, while finally, 2.67\% (4 people) answered that they agree little or not at all.

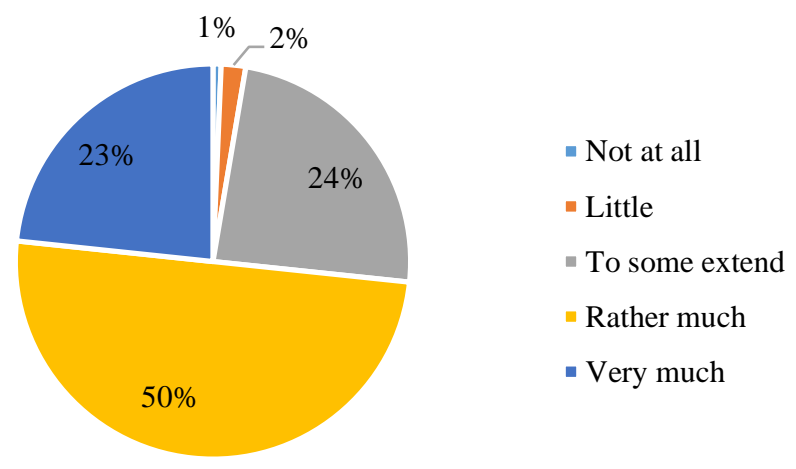

Figure 9. Safety Protocols and Staff Evaluation

Source: Survey Data

The survey participants were then asked to what extent they consider the following skills/characteristics helpful for the staff to ensure the superior quality of the services provided in the pandemic conditions. The results are presented in the following table (4): 
Table 4. Important Staff Skills to Reassure Service Quality during the COVID-19 Pandemic

\begin{tabular}{|l|c|c|c|c|c|}
\hline & Not at all & Little & $\begin{array}{c}\text { To some } \\
\text { extent }\end{array}$ & $\begin{array}{c}\text { Rather } \\
\text { much }\end{array}$ & Very much \\
\hline Empathy & $0.7 \%$ & $2 \%$ & $6 \%$ & $36 \%$ & $55.3 \%$ \\
\hline Communication skills & $0.7 \%$ & $2 \%$ & $10.7 \%$ & $36.7 \%$ & $50 \%$ \\
\hline Discipline in protocols & $0.7 \%$ & $2 \%$ & $4.7 \%$ & $18.7 \%$ & $74 \%$ \\
\hline Professional development ambition & $0.7 \%$ & $4 \%$ & $19.3 \%$ & $45.3 \%$ & $30.7 \%$ \\
\hline Team Spirit & $0.7 \%$ & $2 \%$ & $4.7 \%$ & $20 \%$ & $72.7 \%$ \\
\hline
\end{tabular}

Source: Survey Data

From the table above it seems that team spirit is considered the most important skill or the most important characteristic (92.7\% Rather Much or Very Much), as well as the discipline in the regulations with the same percentages, but $74 \%$ in the Very, followed closely by empathy (71,4\% Rather Much or Very Much). They are followed by communication (86.7\% Rather Much or Very Much) and finally, the ambition of professional development (76\% Rather Much or Very Much). We need to underline here that only one person has answered that none of those mentioned above skills are helpful (thus, the percentage for all skills is $0.7 \%$ ). Participants were then asked to indicate the extent to which they believe staff is affected by the need for job satisfaction during the pandemic (Figure 10). From the chart below, it seems that most of them consider this to be Rather Much or Very Much (86.67\%, 130 people). Also, 10.67\% (16 people) stated that this is to some extent, and finally, 2.67\% (4 people) answered Little or Not at all.

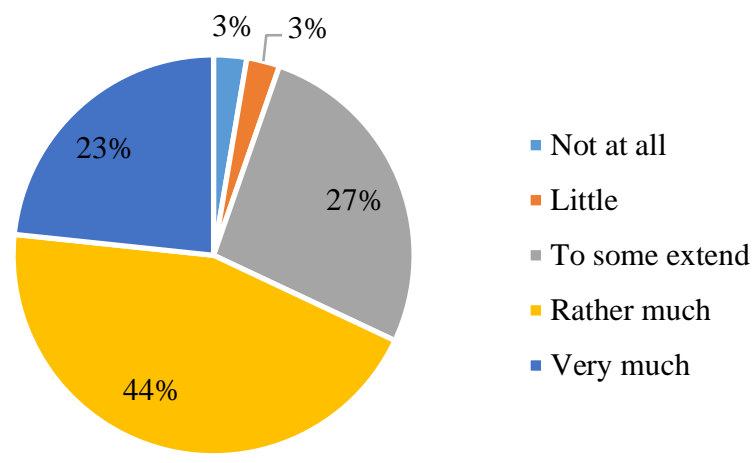

Source: Survey Data

Figure 10. Importance of Job Satisfaction during the COVID-19 Pandemic

In the question to state the extent to which they believe work stress affects the performance of the staff during the pandemic (Figure 11) it seems that the majority consider this to be Rather Much or Very Much (79.33\%, 119 people) important. Furthermore, $18.67 \%$ (28 people) said that this happens to some extent and only two people answered Little.

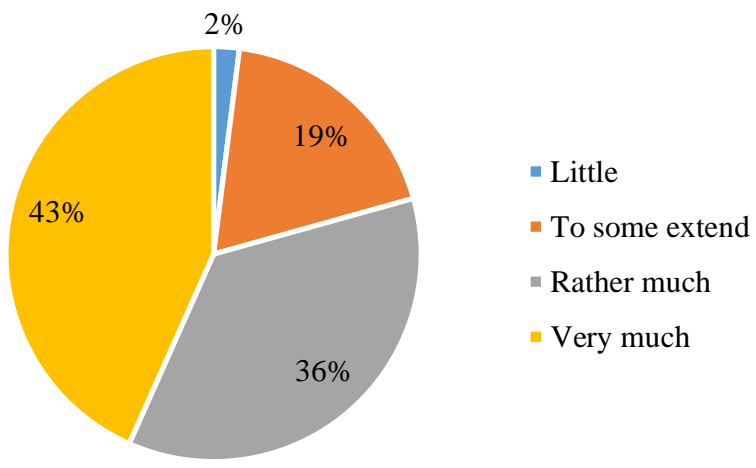

Source: Survey Data

Figure 11. The Effect of Work Stress

Research participants, when asked to indicate the extent to which they considered it helpful to extend the concern of the human resources department on issues concerning the personal lives of employees (Figure 12), 
mainly believe that this is helpful to happen Rather Much or Very Much (64.67\%, 97 people). Furthermore, $26 \%$ (39 people) said it's helpful to some extent, and 9.33\% (14 people) said Little or not at all.

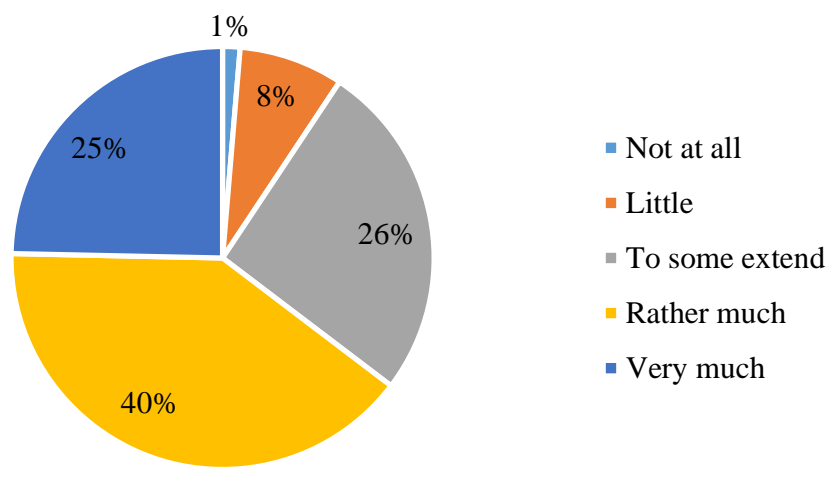

Figure 12. HR Department and Staff Support

Source: Survey Data

The participants were then asked to state to what extent they believed that providing psychosocial motivation to employees would ensure that employees' confidence in the organization was restored during the health crisis (Figure 13). Most of them consider it helpful to have psychological support and motivation (Rather Much or Very Much $-76.67 \%, 115$ people). Furthermore, 20.67\% (31 people) said that it is helpful for this to happen to some extent and finally, $2.66 \%$ (4 people) answered this support has a minus meaning for them.

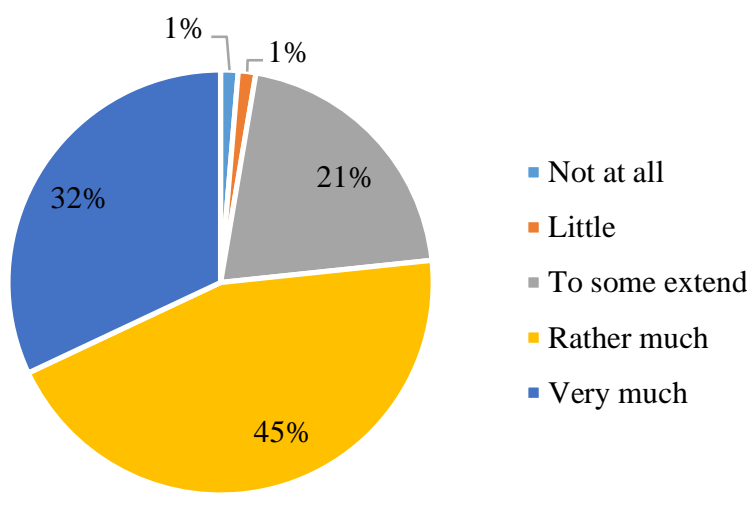

Figure 13. Psychological Support and Motivation

Source: Survey Data

Participants were then asked to state which of the following they consider having the most significant impact on the customer's final assessment of their experience in the hotel during the pandemic (Figure 14). From the diagram below, it seems that the majority considers that what influences the final evaluation of the customer is the quality of service from the staff $(38.67 \%, 58$ people) followed closely by the employees' health behavior (35.33\%, 53 people). The following is the health protocol of the hotel $(19.33 \%, 29$ people) and finally, the range of services provided $(6.67 \%, 10$ people). 


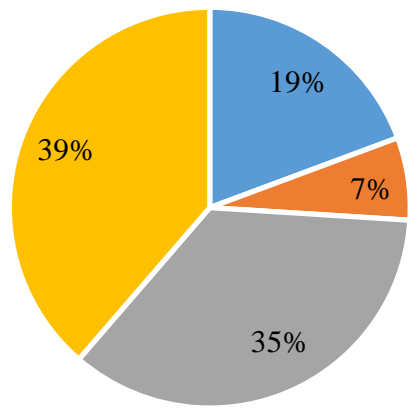

\author{
- The health protocol \\ of the hotel \\ - The range of services \\ provided \\ - The health behavior \\ of the employees \\ $\square$ The quality of service \\ from the staff
}

Figure 14. Factors Affecting Customer Evaluation During the COVID 19 Pandemic

Source: Survey Data

In the next question, the participants were asked to state how important they consider the participation of HRD in the process of staffing the hotel. The chart below shows that most of them consider it important. More specifically, 92\% (138 people) answered Rather Much or Very Much. Also, 6.67\% (10 people) answered To Some Extent and only 2 people (1.33\%) answered Little or Not at all.

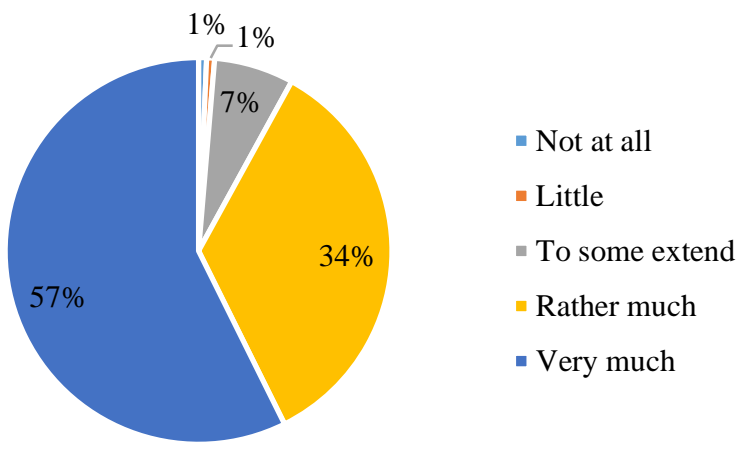

Source: Survey Data

Figure 15. Importance of HRM Participation in the Staffing Process

Participants were then asked to answer the question, "After hiring new staff, how important do you think it is to inform the HR department about the safety protocol followed by the organization?" According to the participant's answers, almost all of them consider it important since $96.67 \%$ answered Rather Much or Very Much and 3.33\% answered to some extent. Participants were then asked to indicate to which extent the staff department is involved in training planning for the staff, especially on health issues (Figure 16). From the chart below, it seems that this happens since 78.67\% (118 people) answered Rather Much or Very Much in most cases. Also, $12.67 \%$ (19 people) answered to some extent and 8.67\% (13 people) answered Little or Not at all.

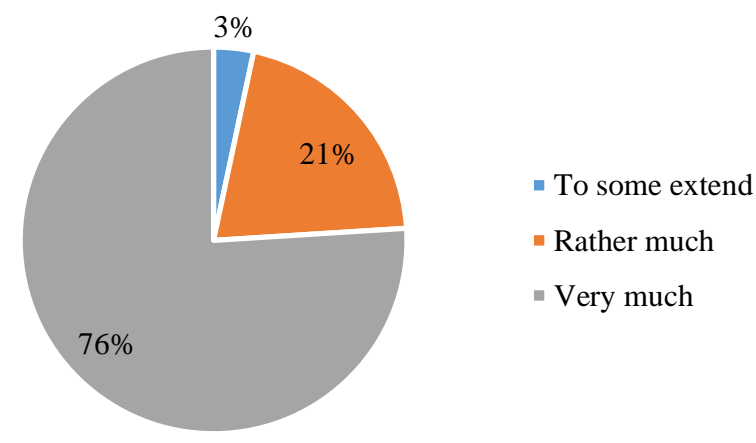

Figure 16. HRM and Training for Safety Protocols 
In the following question, participants were asked whether they consult with HR on issues relevant to their payroll. From the diagram below, it seems that this happens to a large extent since $68 \%$ (102) people state that they discuss issues relevant to payroll with the HR manager during the pandemic, while $26.67 \%$ (40 people) answered to some extent and 5.34\% (8 people) answered Little or Not at all.

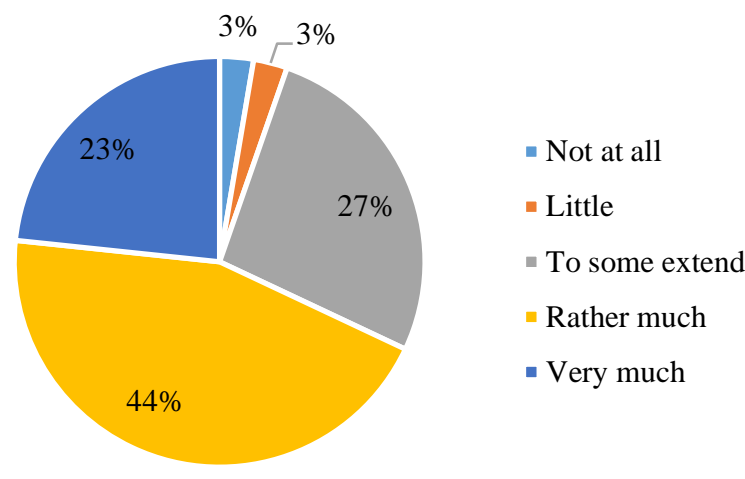

Source: Survey Data

Figure 17. HR and Decision-Making Process on Payroll Issues

In the last of the closed-ended questions, participants were asked to indicate the extent to which they consider the contribution of the human resources department to the following procedures to be helpful. The following table presents the main positioning and dispersion measures. It is reminded that $1=$ Not at all, $2=\mathrm{Little}, 3=$ To some extent, $4=$ Rather much $5=$ Very much.

Table 5. The Contribution of HRM

\begin{tabular}{|c|c|c|c|c|}
\hline Procedure & Minimum value & Maximum value & Average value & Standard deviation \\
\hline Education & 1 & 5 & 4.37 & 0.901 \\
\hline Feedback & 1 & 5 & 4.13 & 0.862 \\
\hline Evaluation & 1 & 5 & 4.18 & 0.812 \\
\hline Work Relations & 1 & 5 & 4.31 & 0.802 \\
\hline Stimulation & 1 & 5 & 4.15 & 0.822 \\
\hline
\end{tabular}

Source: Survey Data

From the table above (5) it seems that the differences are minimal. Education ranks higher than all the procedures $(\mathrm{AV}=4.37, \mathrm{SD}=0.901)$, while work relations $(\mathrm{AV}=4.31, \mathrm{SD}=0.802)$, evaluation ( $\mathrm{AV}=4.18$, $\mathrm{SD}=0.812)$, stimulation $(\mathrm{AV}=4.15, \mathrm{SD}=0.822)$ and feedback procedures $(\mathrm{AV}=4.13, \mathrm{SD}=0.862)$ rank lower.

In the first of the open-ended questions, participants were asked to indicate which needs of their employees they consider to be most important to be covered under the pandemic conditions (earnings, advancement, safety, etc.) and why. Some of the answers are presented as examples.

$>$ "Security and participation in decision-making, because, on the one hand, employees have increased work stress due to the contagiousness of the virus and, therefore, need a sense of security in the performance of their duties and, on the other hand, participation in decision-making enhances the sense of self-fulfillment and their work stress is reduced".

$>$ "In these conditions, staff consider the issue of their safety more important than anything else".

$>$ "In the difficult and insecure period, we are going through, the sense of health security, mental and physical, is everyone's priority. Fixed earnings mean respect and recognition of each employee's efforts and motivate them to offer more. They feel safe and that has an impact".

$>$ "Basic Needs and Security Needs are always prioritized by the executive (Maslow). "Consequently, I would put, salary increase, workplace safety, teamwork, leadership and responsibility, personal development and self-realization".

$>$ "Continuous training and mobilization with anthropocentric methods".

$>$ "Safety in health and work, that's the only way the employee works in general".

$>$ "Security and compliance with the measures by the administration/owner, but also the valid information on labor issues".

$>$ "Assurance that they will have a job and their earnings will not be reduced working in an always safe health environment".

"Staff safety plays a dominant role; many see the opportunities given by the pandemic". 
$>$ "Relationship of trust and security as well as compliance with the agreement between the company and the employee. As long as the respective agreement and its terms are fulfilled, there will be a win-win relationship between the company and the employee. Unilateral change of agreement by the company will disrupt the safety, mental mood and ultimately the efficiency of the employee. Satisfactory earnings based on the professional profile of each employee, but also the responsibilities they assume.

In the next open-ended question, the participants were asked to state the positive or negative effect of the hotel's health and hygiene protocols on employees' sense of security. From the analysis of the answers, it seems that the majority consider it as positive. Some of the answers are presented as examples.

$>$ "Implementing increased health protocols has a positive effect on employees' sense of security".

> "Implementing health and hygiene protocols increases the sense of security and reduces employee uncertainty".

$>$ "It is a given that the general feeling of security in a company in key issues (consistency of salary payment, fair and objective evaluation on performance and daily life, quality systems and the possibility of development) is important. Especially when the critical issue of health is added to the above. The existence and faithful implementation of a reliable operating protocol, therefore, increases the sense of security of employees".

$>$ "They feel more the need for proper team cooperation".

$>$ "Adequate security measures can only have a positive effect. The sense and confidence of health protection, the recognition that HR management has as first concern the health of employees. "Mutual respect for compliance with the protocols".

> "It is very important; the health and hygiene protocols should be part of the hotel culture".

$>$ "Serious implementation of the protocols helps the employees feel safe".

$>$ "Proper training and compliance with health and hygiene protocols by all parties (management and employees) can only have a positive effect".

$>$ "There are older employees that are afraid for their lives and want their work environment not to endanger them".

$>$ "It goes without saying that the Hygiene and Safety protocols, together with their proper implementation have a positive effect on all the hotel staff, giving them a sense of safety and security".

$>$ "The positive side is the safety of the customers and the reliability, in the image of the hotel, the negative effect concerns the employees who malfunction during working hours and, certainly, that affects customer satisfaction and behavior".

$>$ "Health protocols ensure a sense of security for employees, but at the same time create stress for them, firstly because they have to be constantly vigilant and keep them as a rule and secondly because some measures such as masks restrict employees to create a warmer and a welcoming atmosphere for the guests".

$>$ "Employees' sense of security is basic and primary! That way the employee can achieve greater results".

$>$ "By enforcing the health protocols set by the hotel, employees feel more familiar with their work environment, they also feel a sense of fairness and equal treatment as well as development prospects, and this leads to better work performance and better psychology".

The negative aspects were the difficulties in the way of adapting and implementation health protocols, the time-consuming procedures, the insufficient compliance of the protocols on behalf of the customers, but also by some hotels, the increase of the workload with the same earnings, the feeling of insecurity that they can be infected at any time, as well as the negative impact on staff psychology. In the last question, participants were asked to indicate what they consider to be key points on which the hotel's communication policy towards employees during the pandemic should be based. Some of the answers are presented as examples.

$>$ "Emphasis on staff and customer safety will help improve working life and increase employee productivity. Persistence in adhering to the rules of the protocol and providing all the necessary measures, instruments and training will ultimately contribute to the sense of security of all involved."

$>$ "Direct daily contact, motivation by example and motivation for the best employees".

$>$ "Constant updating, if possible, on a daily basis".

$>$ "Continuous feedback, honesty and respect for staff needs".

$>$ "Training - vigilance - flexibility - adherence to regulations".

$>$ "Continuous information, teamwork, protection of employees".

$>$ "Clear Vision of the Hotel, Values We Advocate, Corporate Culture, Customer Focus, Collaborative Atmosphere". 
$>$ "Information, Training, Organization, Perseverance in Security".

$>$ "Clear instructions and development of the sense of trust".

$>$ "Health, care, assistance".

$>$ "Salary and moral support".

$>$ "In the safety and observance of the health protocols of employees \& visitors".

$>$ "Internal communication of department heads and team effort".

$>$ "The feeling of security in terms of employees' health as well as financial incentives e.g., NOT to reduce salaries or benefits".

$>$ "Health and hygiene protocols and their implementation, not counterfeit certificates and sloppy disinfection".

$>$ "Ensuring safety, frequent communication, interest in the mental health of staff".

$>$ "Proper training and updating at regular times".

$>$ "Updates!!! Regular communication with the staff, to increase safety. When hotel HR management is absent, the employees are upset and the trust in the management is lost".

$>$ "Honesty, flexibility, professionalism \& motivation".

$>$ "Support, immediacy and constructive dialogue".

$>$ "To listen to their needs and cover them the best way".

$>$ "The salary according to the law, the breaks, the ideal working conditions and the decent stay, but also the provision of ideal living conditions".

$>$ "Honesty, positive climate in work, adhering health protocols".

$>$ "Payment consistency, systematic Covid-19 tests, real and not substantial compliance of health protocols".

$>$ "In communication policy, the distribution of information plays an important role, respecting the hierarchy in both directions. The information and instructions should be distributed by the general manager to the senior executives who, in turn, will pass it on to the employees of their departments. Conversely, when employees encounter or identify any operational issue, they must inform their supervisors who, in turn, will inform the general manager. This way of communication between management and employees can be carried out either with frequent meetings in compliance with the health protocols or when it comes to simple issues, communication and information via e-mail".

$>$ "Communication policy refers to the customer. Thus, if we consider that each employee is also an ambassador of the hotel they work for, they should communicate the health safety protocol that is faithfully applied by the hotel and, of course, the high level of service".

$>$ "Participation in decision making".

$>$ "The hotel should be close to the employees and listen to the problems of everyday life as there is great insecurity and anxiety".

$>$ "Security, Protection, Team spirit, Continuous information".

$>$ "Psychological support and presence to assure the safety of employees and the conscious presence of the manager".

$>$ "To spend time listening, observing, identifying employees' weaknesses and proposing solutions".

$>$ "Communication is the most important process for exercising management at all levels. Without it, no organization or business can function. If we, as management, cannot communicate with employees, we cannot fulfill the purpose of our work, we will not be able to motivate employees or exercise some degree of management".

\section{Discussion}

In times of crisis like the pandemic of the COVID-19, hotel resilience is strongly dependent upon the organization and performance of their labor force. HR manager, his/her leadership style and skills determine the effectiveness and productivity of the labor force (Kara et al., 2013). Therefore, the competent leader should find or open channels of communication with the workforce and ensure that the vision and the goals will be understood and followed by all employees (Susser and Tyson, 2020). Regarding the first research question: To what extent do the managers' strategies contribute to the achievement of the hotel's goals? Is it legitimate for managers to penetrate the unit strategy and influence the direction of their decisions and practical applications?

The responses of the survey participants showed that most of them consider it helpful during the current conditions of the pandemic to deepen the personal relationships between employees and HR managers, as such an approach can help achieve the hotel's goals. The Human Resources Manager (HRM) role is crucial in such conditions, where insecurity is prevalent and can cultivate an atmosphere of safety in the workplace. The hospitality industry is among those that have been hit hardest, so job insecurity is a dominant pathogen among 
employees for a reasonable period, which HRD should address. Such an arrangement is necessary as job insecurity can significantly affect employee performance and favor mobility and constant staff turnover. In addition, given the seasonal operation of most hotels, mobility or lack of staff is likely to be a deregulating factor in terms of their operation. At the same time, it is likely to reduce the ability to respond immediately to customer needs and, ultimately, reduce the quality of services provided. It is, therefore, important to create work environments in which employees can work stress-free (Yung et al., 2021).

Survey participants believe that HRM can guide staff behavior on prevention and health safety issues. The creation of autonomous and horizontal organizational structures within the work environment can motivate employees to express themselves and seek the attention they need in the context of mutual communication. In addition, to reduce job insecurity, it is helpful to favor the participation of employees in decision-making processes so that they consider their job and opinion as an important part of the organization and understand the broader difficulties faced by the hotel. In such a context, it is appropriate for the HR manager to promote the exchange of previous experiences related to overcoming challenges or transmitting know-how from previous times of crisis (Yung et al., 2021). In the present research, the prevailing view was that the participation of working groups in the decision-making process on labor issues is helpful. In addition, the managers who participated in the research stated that the role of HRD in the staffing process of the hotel is significant. Regarding the second survey question: What are the new needs that arise for the employees of the hospitality sector in the current conditions of the health crisis? Changing priorities to employees' personal needs can affect their performance and productivity? What are the points that HR manager focuses on when motivating employees to meet these needs?

The managers' responses showed that the most important skill or characteristic for dealing with the problems during crisis is team spirit, commitment to health protocols and regulations, communication skills, and the ambition of professional development on behalf of the employee. One issue that has emerged in the present study is that staff were affected by the need for job satisfaction during the pandemic, while they largely agree that work stress affects staff performance during the pandemic. For this reason, they consider it helpful to expand the concern of the HRM on issues concerning the personal life of employees. They also believe that by providing psychosocial motivation to employees, it is possible to ensure the establishment of employees' trust in the hotel. The research of Stergiou and Farmakis (2020) demonstrates the impact of the pandemic on staff in the hospitality industry. They concluded that the main factors influencing the rate of abstention during the pandemic are, of course, the fear of infection, placing the family as a priority, the sense of lack of information about health conditions on behalf of the manager and the broader reduction of the employee's trust in the manager. All the above can help a manager understand the reorganization in the employee's value scale and design an incentive plan that responds to the new data. Attention is now shifting from increasing financial rewards or boosting employees' personal job satisfaction to other priorities, as modern incentives relate to ensuring their health and the need for adequate information. Regarding the third survey question: What is the change that takes place in the concept and role of the leader during the pandemic and the period after it? How do the safety and health components affect the leader's vision and goals and how the unit's rhetorical and communication policy is shaped towards employees?

The managers who participated in the survey consider that, after hiring new staff, it is important that the human resources department informs them about health protocols followed by the hotel. At the same time, the same department owns to formulate training programs in health protocols for them. The role of HR is considered important in issues related to staff training, labor relations management, and to a lesser extent in the processes of evaluation, motivation, and feedback. From their answers to the open-ended questions, it seems that the insecurity that prevails in the industry emerges as a significant issue. For this reason, they focus on strengthening the sense of security and expanding the participation of employees in decision-making. They note that on the one hand, employees have increased work stress due to the contagiousness of the virus and, therefore, need a sense of security while they are carrying out their duties and, on the other hand, participation in decision-making enhances the sense of self-fulfillment of their professional goals, while reducing work stress and consequently leading to better service to customers, which certainly leads to the fulfillment of the hotel's goals. Finally, regarding the changes in the rhetorical and communication policy of the hotel to the employees, the insistence on the observance of the rules of the health protocol and the provision of all the necessary measures, instruments, and training was emphasized, while the direct and daily contact, and the motivation by example, as well as providing incentives to the best employees are considered advisable. At the same time, particular importance is given to providing a clear vision, clarifying the values that the hotel stands for, and developing a corporate culture, which will be customer-oriented and a collaborative atmosphere. Finally, it is pointed out that in the communication policy, the distribution of information plays an important 
role, respecting the hierarchy in both directions. The above is in line with what Zhang et al. (2020) research, emphasizing that the issue of protecting the health of employees and controlling the spread of the virus, as well as the cultivation of a "corporate ethic" which sets health as a priority, is an important concern of HRM. This ethic can well serve as a means of motivating employees, who feel exposed to health risks due to daily personal contact with other staff members and with customers.

The present work has a significant limitation, that of the absence of a specific sampling method. The choice of a convenience sample does not provide the possibility for generalization of the conclusions despite the satisfactory sample size. In addition, the survey focused on hotels on two islands, which are predominantly tourist destinations in the country, but are not able to reflect the reality experienced by the hotel industry in Greece. For this reason, it is proposed to conduct similar surveys with a larger sample from hotels across the country.

Author Contributions: Conceptualization: Aivalioti Ypapanti; data curation: Aivalioti Ypapanti; formal analysis: Aivalioti Ypapanti and Constantoglou Mary; investigation: Aivalioti Ypapanti; methodology: Aivalioti Ypapanti and Constantoglou Mary; project administration: Aivalioti Ypapanti; resources: Aivalioti Ypapanti; software: Aivalioti Ypapanti; supervision: Aivalioti Ypapanti and Constantoglou Mary; validation: Aivalioti Ypapanti and Constantoglou Mary; visualization: Aivalioti Ypapanti and Constantoglou Mary; writing - original draft: Aivalioti Ypapanti; writing - review \& editing: Mary Constantoglou.

Funding. There is no funding for this research.

\section{References}

1. Agarwal, P. (2021). Shattered but smiling: Human resources management and the wellbeing of hotel employees during COVID-19. International Journal of Hospitality Management, 93. [Google Scholar] [CrossRef]

2. Bradberry, T., Greaves, J. (2006). The emotional intelligence Quick Book, Fireside. New York. [Google Scholar]

3. Carnevale J.B., Hatak, I. (2020). Employee adjustment and well-being in the era of COVID-19: implications for human resources management. J. Bus. Res., 116, 183-187. [Google Scholar] [CrossRef]

4. Cohen, L., Manion, L., \& Morrison, L. (2008). Educational research methodology. Routledge. London. Available at: [Link]

5. Creswell, J.W. (2011). Research in Education: Design, conduct and evaluate quantitative and qualitative research. Pearson Education Inc. New Jersey. Available at: [Link]

6. Gui, C., Luo, A., Zhang, P., and Deng, A. (2020). A meta-analysis of transformational leadership in hospitality research. International Journal of Contemporary Hospitality Management,. 32(6), 2137-2154. [Google Scholar] [CrossRef]

7. Hashim, J., Ismail, Y., Hassan, A. (2016). Formality of HRM practices matters to employees satisfaction and Commitment. Journal of Human Resources, 4(1), 47-64. [Google Scholar] [CrossRef]

8. Hu, X., Yan, H., Casey, T., Wu, C.H. (2020). Creating a safe haven during the crisis: how organizations can achieve deep compliance with COVID-19 safety measures in the hospitality industry. International Journal of Hospitality Management, 92. [Google Scholar] [CrossRef]

9. INSETE (2020). South Aegean District: Annual report on competitiveness and structural arrangement in the tourism sector for the year 2019. Available at: [Link]

10.Kara, D., Uysal, M., Sirgy, M.J., Lee, G. (2013). The effects of leadership style on employee well-being in hospitality. International Journal of Hospitality Management, 34, 9-18. [Google Scholar] [CrossRef]

11.Karatepe, O.M., Rezapouraghdam, H., Hassannia, R. (2020). Job insecurity, work engagement and their effects on hotel employees' non-green and nonattendance behaviors. International Journal of Hospitality Management, 87, 102472. [Google Scholar] [CrossRef]

12.Kehoe, R.R., Wright, P.M. (2013). The impact of high-performance human resource practices on employees' attitudes and behaviors. Journal of Management, 39(2), 366-391. [Google Scholar] [CrossRef]

13.Kim S.S., Im, J., Hwang, J. (2015). The effects of mentoring on role stress, job attitude, and turnover intention in the hotel industry. International Journal of Hospitality Management, 48, 68-82. [Google Scholar] [CrossRef]

14.Laskarin, M. (2017). The impact of hotel employee satisfaction on hospitability performance. Tourism and hospitality management, 23(1), 105-117. [Google Scholar] [CrossRef] 
15.Liu-Lastres, B., Schroeder, A., and Pennington-Gray, L. (2019). Cruise line customers' responses to risk and crisis communication messages: an application of the risk perception attitude framework. Journal of Travel Research, 58(5), 849-865. [Google Scholar] [CrossRef]

16.Najam, U., Ishaque, S., Irshad, S., Salik, Q., Khakwani, M., Liaquat, M. (2020). A Link Between Human Resource Management Practices and Customer Satisfaction: A Moderated Mediation Model. Sage open, 10(4). [Google Scholar] [CrossRef]

17.Nichols, C., Chatterjee, H., Trendler, C. (2020). Four behaviors that help leaders, in Coronavirus: Leadership and Recovery: The Insights You Need from Harvard Business Review, Harvard Business Press. Available at: [Link]

18.Qureshi, K., Gershon, R., Sherman, M., Straub, T., Gebbie, E., McCollum, M., Erwin, M., Morse, S. (2005). Healthcare worker's ability and willingness to report to duty during catastrophic disasters. Journal of Urban Health, 82(3), 378-388. [Google Scholar] [CrossRef]

19.Salas-Vallina, A., Alegre, J., Lopez- Cabrales, A. (2020). The Challenge of Increasing Employees' Wellbeing and Performance: How Human resources Management Practices and Engaging Leadership Work Together Toward Reaching This Goal. Human Resource Management, 60(3), 333-347. [Google Scholar] [CrossRef]

20.Stephan, U. (2018). Entrepreneurs' mental health and well-being: A review and research agenda. Academy of Management Perspectives, 32(3), 290-322. [Google Scholar] [CrossRef]

21.Stergiou, P.D., Farmaki, A. (2020). Ability and willingness to work during COVID-19 pandemic: Perspectives of front-line hotel employees. International Journal of Hospitality Management, 93, 102770. [Google Scholar] [CrossRef]

22.Susser, P., Tyson, T. (2020). What are companies legal obligation, in Coronavirus: Leadership and Recovery: The Insights You Need from Harvard Business Review. Harvard Business Press. Available at: [Link]

23.UNWTO (2020). Worst year in tourism history with 1 billion fewer international arrivals. Available at: [Link]

24.Verikios, G., Sullivan, M., Stojanovski, P., Giesecke, J., Woo, G. (2016). Assessing regional risks from pandemic influenza. World Economy, 39(8), 1225-1255. [Google Scholar] [CrossRef]

25.Wong, K.F.A., Seongseop, K., Jungkeun, K., Heesup H. (2021). How the COVID-19 pandemic affected hotel Employee stress: Employee perceptions of occupational stressors and their consequences. International Journal of Hospitality Management, 93, 102798. [Google Scholar] [CrossRef]

26.Xue, Y., Fan, Y., and Xie, X. (2020). Relation between senior managers' safety leadership and safety behavior in the Chinese petrochemical industry. Journal of Loss Prevention in the Process Industries, 65 , 104142. [Google Scholar] [CrossRef]

27. Yacoub, L., El Hajjar, S. (2021). How do hotels in developing countries manage the impact of COVID-19? The case of Lebanese hotels. International Journal of Contemporary Hospitality Management, 33(3), 929-948. [Google Scholar] [CrossRef]

28.Yang, F.X., Lau, V.M.C. (2019). Evil customers, an angel boss and coopetitive coworkers: burnout of frontline employees. International Journal Hospitality Management, 83, 1-10. [Google Scholar] [CrossRef]

29.Zhang, J., Xie, C., Wang, J., Morrison, A.M., and Coca-Stefaniak, J.A. (2020). Responding to a major global crisis: the effects of hotel safety leadership on employee safety behavior during COVID-19. International Journal of Contemporary Hospitality Management, 32(11), 3365-3389. [Google Scholar] [CrossRef] 